\title{
(A)phantasia and Severely Deficient Autobiographical Memory: Scientific and Personal Perspectives.
}

\author{
Nicholas Wynn Watkins $\mathbf{s}^{\mathrm{a}, \mathrm{b}, \mathrm{c}}$ \\ nickwatkins62@physics.org
}

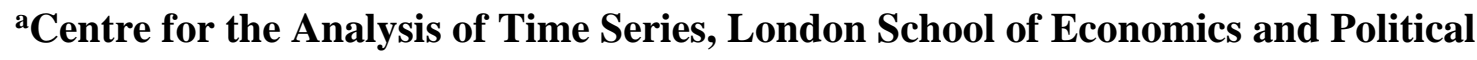
Science, Houghton St, London, WC2A 2AE, UK

\author{
${ }^{\text {b} F a c u l t y ~ o f ~ S c i e n c e, ~ T e c h n o l o g y, ~ E n g i n e e r i n g ~ \& ~ M a t h e m a t i c s, ~}$ \\ School of Engineering \& Innovation, Open University, Milton Keynes, UK \\ cCentre for Fusion, Space and Astrophysics, University of Warwick, Coventry, CV4 \\ 7AL, UK
}

\begin{abstract}
I address two interlinked aspects of the diversity in our experiences of memory and the mind's eye. I summarise the long-appreciated role of imagery in mathematics and the physical sciences, and contrast it with the evidence that some scientists have had limited or zero imagery. I then recount the story of how I became aware of my own lack of mental imagery, and the accompanying deficit in my episodic memory, how I have sought scientific understanding of these conditions, and how they have affected my life.
\end{abstract}

Keywords: Episodic memory; Severely Deficient Autobiographical Memory; Mental Imagery; Aphantasia; Mind's Eye.

1.1 Introduction: The contributions in this special issue touch on many of the areas of human creativity in which visual imagery has played a key role, and my paper, derived from my contribution to the "Eye's Mind" conference in 2016 supported by the AHRC, aims first to briefly survey the role of imagery in mathematics and the physical sciences, but it also has a second, more personal aim.

Three human visual capacities are so familiar that most people take them for granted: i) visual imagination in a "mind's eye", ii) an "episodic" aspect to memory that travels back in time to give a first person sense of experiencing again one's own past sights, sensations and emotions, and iii) its opposite, first person "mental time travel" into an anticipated future. But we really shouldn't be so blasé. Indeed it has been argued (Tulving, 2002) that episodic memory and the first-person sense of time are among the most remarkable products of evolution. Because the faculties noted above are so universal, they can be taken to be essential aspects of being human, but in the last two years it has become much more widely appreciated that a significant number of people actually lack mental imagery ("aphantasia"; Zeman et al, 2015), and that some otherwise healthy people have severely deficient autobiographical memory (SDAM; Palombo et al, 2015). I am one such person. I have been aware of my aphantasia and SDAM, and I have been seeking to understand the reasons behind them for almost 20 years. The rest of this paper gives a report of my findings (albeit an unusual one in which first person testimony will figure large). 
1.2 Scientific Aspects: The role of the nearly universal human faculty of mental imagery (Kosslyn, 1994; Thomas, 1997; Pearson et al, 2013; MacKisack et al, 2016) in scientific and mathematical creativity has long attracted research interest (Hadamard, 1945; Ferguson, 1977; Miller, 1986; Mancosu et al, 2005; Brewer and Schommer-Aikins, 2006; Rocke, 2010). Probably the most celebrated instance is the physical chemist Kekule's account (Benfy,1958;Rocke, 2010) of how he dreamt the structure of the benzene ring: "long rows, ... all twining and twisting in snake-like motion ... One of the snakes had seized hold of its own tail, and the form whirled mockingly before my eyes. As if by a flash of lightning I awoke; and ... spent the rest of the night in working out the consequences of the hypothesis" (Benfy, 1958). By his own account, such visualisation was a frequently exercised faculty, his "mental eye" having been "rendered more acute by repeated visions of the kind". The benzene dream was apparently preceded by an earlier daydream on a London bus about chemical valence, where "the atoms were gamboling before my eyes" (Benfy, 1958).

Many physicists have employed visualisation, for example space scientist Jim Dungey, interviewed in 1986 saying "I saw the picture ... in three dimensions, whereby the electric field over the polar cap fitted in with the reconnection picture ... Then, I think if I can, everybody can" (Dungey, 1986). Albert Einstein seems to have been an archetypal visualiser. His most famous thought experiment, to imagine riding alongside a beam of light, was conducted as a 16-year old student at a Pestalozzi school in Switzerland (Isaacson, 2015). Many years later he responded to a questionnaire about scientific creativity by the French mathematician Jacques Hadamard (see Appendix II of Hadamard (1945)) by saying "The psychical entities which seem to serve as elements in thought are ... more or less clear images which can be 'voluntarily' reproduced and combined. [Some are] of visual and some of muscular type. Conventional words or other signs have to be sought for laboriously only in a secondary stage."

Pauli even went as far as collaborating with Jung to investigate the latter's "primordial images" as the bridge between sense perceptions and concepts (Zabusky, 1984). However, even enthusiastic users of mental imagery have urged caution. Kekule, after all, warned us to "beware of publishing our dreams until they have been tested by the waking understanding". Although Farmelo (2009) reports that Dirac was "always uneasy with algebraic approaches to physics and with any mathematical process he could not picture", it is striking that he nonetheless prefaced his "Principles of Quantum Mechanics" by saying: "the laws of physics do not govern the world as it appears in our mental picture in any very direct way, but instead they control a substratum of which we cannot form a mental picture without introducing irrelevancies" (Dirac, 1930). Although Feynman greatly admired Dirac, his famous diagrams were a direct response to the latter's implicit challenge to find a pictorial tool that could be of value in quantum mechanics (Wuetrich, 2010).

The training of physicists recapitulates the historical process, and generations of students have struggled with the transition between Newtonian mechanics and Maxwell's electrodynamics, where many concepts benefit greatly from visualisation, to quantum mechanics, a theory constructed using objects as foreign to our direct sensory experience and intuition as the probability amplitude wavefunction which solves Schrodinger's equation (e.g. Longair, 2003;Miller, 1986).

The rigour exemplified by the scientific method is of course essential to making science as objective as possible, by detaching its conclusions from the thought processes of any one individual, no matter how exceptional, and subjecting them to experimental test. In mathematics, where proof rather than experiment is the final arbiter, an even more fundamental disdain for visualisation has existed 
in some quarters. Lagrange for example proudly said "you won't find any drawing in my book", while the collective of French mathematicians who published as "Nicolas Bourbaki" sought to eliminate any need for visualization, part of a broader distrust of geometry in proof. In Marjorie Senechal's interview (Senechal, 1998), Bourbaki founder member Pierre Cartier gives this fascinating reply to her question about the sources of this disdain: "... The Bourbaki were Puritans, and Puritans are strongly opposed to pictorial representations of truths of their faith. [...] So, what were the reasons? The general philosophy as developed by Kant, certainly. [...] And then there was the idea that there is an opposition between art and science. Art is fragile and mortal, because it appeals to emotions, to visual meaning, and to unstated analogies. But I think it's also part of the Euclidean tradition. In Euclid, you find some drawings but it is known that most of them were added after Euclid, in later editions. Most of the drawings in the original are abstract drawings. You make some reasoning about some proportions and you draw some segments, but they are not intended to be geometrical segments, just representations of some abstract notions. [...] The analytical spirit was part of the French tradition and part of the German tradition. And I suppose it was also due to the influence of people like Russell, who claimed that they could prove everything formally-that so-called geometrical intuition was not reliable in proof."

In stark contrast to the Bourbaki was a mathematical visionary (and visualiser) Benoit Mandelbrot, whose own uncle was one of the founders of the Bourbaki, and whose life's work was in some sense a riposte to their approach. Describing the way in which he mastered mathematics as a teenager he said: "I didn't learn much algebra. I just learnt how better to think in pictures because I knew how to do it. I would see them in my mind's eye intersecting, moving around or not intersecting and could describe what I saw. Having described it, I could write two or three lines of algebra, which, is much easier if you know the results than if you don't" (Mandelbrot, 1995). In later years Mandelbrot's very visual approach enabled him to see deep geometrical links between mathematics and disciplines including physics, economics and the geosciences that few people would have connected, but this very farsightedness seems to have made it difficult for him to explain what he had seen, Mandelbrot (2012) and some innovations of his from 50 years ago are only now being rediscovered, a process described by Watkins (2016).

However, the process of science is not just deduction by individuals but construction by a community. The remarkable geometric abilities of some blind mathematicians such as Morin have given insight into the varieties of mathematical imagination and quite how diverse this community is. Morin himself noted that "disabilities like blindness, ... reinforce one's gifts and one's deficits" and has drawn attention to two sorts of mathematical imagination: "time-like" which deals with information by proceeding through a series of steps, at which he was not good, a deficit worsened by blindness, and "space-like" which allows one to comprehend information all at once, at which he excelled (Lawrence, 2002).

Much of the work on mental imagery in science has either concerned naturally strong imagers or people who have lost sight while retaining (or losing) a "mind's eye". The famous work of Galton $(1880,1883)$ recounted by James $(1890)$, thus remains a particularly important exception. The responses of some recipients of his questionnaire: "amazed [him]. [He] had begun by questioning friends in the scientific world, as they were the most likely class of men to give accurate answers concerning this faculty of visualising, to which novelists and poets continually allude, which has left an abiding mark on the vocabularies of every language ..." He was astonished to find that "the great majority [sic] of the men of science to whom [he] first applied protested that mental imagery was 
unknown to them, and they looked on [him] as fanciful and fantastic in supposing that the words 'mental imagery' really expressed what [he] believed everybody supposed them to mean." When Galton extended these first approaches to a larger sample of 100 "men of science", the majority did not in fact lack imagery but even so up to six of his respondents seem to have reported themselves to be truly without experiences of visual imagery. The work of Burbridge (1994) has made it possible to establish who they were: "(95, Charles Piazzi Smyth). No power of visualising ... (96, Major John Herschel FRS). It is only as a figure of speech that I can describe my recollection of a scene as a' mental image' which I can 'see' with my ' mind's eye.' (97, Sir Edmund Du Cane). No individual objects, only a general idea of a very uncertain kind. (98, George John Romanes FRS). ... My memory is not of the nature of a spontaneous vision, ... ideas are not felt to be mental pictures, but rather the symbols of facts. (99, Sir James Paget FRS). ... impressions are in all respect so dim vague and transient, that I doubt whether they can reasonably be called images. They are incomparably less than those of dreams. (100, Sir J. Henry Lefroy FRS). My powers are zero. To my consciousness there is almost no association of memory with objective visual impressions. I recollect the breakfast table, but do not see it."

It is striking that James (1890) seems to have completely accepted Galton's findings, saying that some people "undoubtedly have no visual images at all worthy of the name, and instead of seeing their breakfast-table, they tell you that they remember it or know what was on it. This knowing and remembering takes place undoubtedly by means of verbal images". Faw, (2009) argues that both Galton and James may have had relatively weak imagery themselves. Galton reported that he could only "visualise with effort; saying that "before [he] thought of carefully trying, [he] should have emphatically declared that [his] field of view in the dark was essentially of a uniform black, subject to an occasional light-purple cloudiness and other small variations" (Galton, 1883). However, after Galton's efforts to " habituat[e him]self to examine it with the same sort of strain that one tries to decipher a signpost in the dark, [he] found out that this is by no means the case, but that a kaleidoscopic change of patterns and forms is continually going on, but they are too fugitive and elaborate ... to draw with any approach to truth." Even after practise, they "disappear out of sight and memory the instance [he began] to think about anything ...", a finding which greatly interested Hadamard (1945), who was concerned with whether images accompanied thought or were antithetical to it, as he felt to be the case for himself. Even Galton's critic, Bain (1880) agreed that there was a "natural antagonism of pictorial aptitude and abstract thought".

James' enthusiasm may not have been typical, and Burbridge (1994) notes that Galton's work in general encountered a mixed response among his peers. Galton (1880) attracted a hostile comment from Bain (1880) almost immediately: "At first blush it seems to be nothing more than a determination, by accurate statistics, of the relative preponderance of certain varieties of mind that we already know to exist. ... That certain individuals ... have a great or a small visualising memory, is an important fact as regards them ... [but] it contributes nothing new to science; the existence of such variations has been known at all times [my emphases]". Burbridge (1994) shows that Galton was indeed aware of previous interest in the range of individual differences from Fechner, Erasmus Darwin and (Wilhelm) "Wundt of Heidelberg" but it is not clear that they had noticed the existence of non-imagers before him.

Despite his paper's scathing tone, Bain's plea for a more balanced appraisal remains relevant today: "The ear plays a part in our intellectual being second only to sight; the power of language is the rival power to visual conception, and, in the texture of the memory, may take its place. Something, 
therefore, should be known respecting the linguistic memory also, without which no statement of the intellectual peculiarity of the individual is complete". Indeed, Paivio's celebrated Dual Coding Theory (Paivio, 1971;1990;2007) offers a modern approach to the very image-word dichotomy that Bain was referring to. It was characterized by one of my reviewers as "a synthesized view that is inclusive with both the imaginal and verbal systems playing prominent roles. ... [it] challenges the compartmentalized, either/or semantic vs. imagery view of cognition and instead advocates a proposition that the secret lies in the unification of the two great coding systems for efficacious memory and higher order levels of cognition".

The new findings of Zeman et al (2015), taking up the enquiry started by Galton, are already giving rise to developments in many directions. I would like to propose that one avenue should be to ask how the wide spectrum of mental imagery among scientists may have affected the evolution of science itself, informed by the growing awareness that imagery can be low or absent as well as strong. I am presently aware of only a very few documented living aphantasic scientists or technologists, with perhaps the highest profile examples being geneticist Craig Venter (Grinnell, 2016) and software engineer Blake Ross (Ross, 2016). The past is not much more illuminating, although we do know who Galton's aphantasic respondents were. In view of this paucity of information, I will give a brief account in the next section of how I became aware of my own aphantasia, and of my concurrent SDAM, noting some of the wide variety of published material which helped me during my search for more insights, and offering some thoughts on how it has affected me in my work in physics. I hope that even this limited data point will be of some value to this nascent area of research. I also think that an account of how I became aware of my situation in a time before widespread awareness of SDAM and aphantasia may already be of some historical and "control" value in itself.

1.2 Personal Aspects: "I saw it in my mind's eye"... "it took me right back"..."where do you see yourself in 5 years' time?". These phrases are so familiar that most people take for granted the three human capacities they embody: visual imagination; "episodic" memory that directly reexperiences one's own past sights, sensations and emotions; and its temporal opposite, first person "mental time travel" into an anticipated future. Most people, but not all, as was apparently first noticed by Galton (1880) and is now becoming clearer through the work of Palombo et al (2015) on SDAM and Zeman et al (2015) on aphantasia. I am somebody who lacks all these three capacities, and the rest of this paper is about my quest, both as a physicist and a person, to understand why, and to come to terms with these differences. But first, in answer to the reader's inevitable questions, I will try to describe what, for me, it is like to be aphantasic and to have SDAM, though I must caution that mine may not be representative of other people's experiences.

I think the best way I can describe my aphantasia is to say that I am unaware of anything in my mind except these categories: i) direct sensory input, ii) "unheard" words that carry thoughts, iii) "unheard" music, iv) a kind of "invisible imagery", which I can best describe as sensation of pictures that are in a sense "too faint to see", v) emotions, and vi) thoughts which seem too "fast" to exist as words. The "invisible imagery" is a sensation of having an image that one feels to be there but one can't see, as opposed to, say, a faint image like the "misty watercolour memories" of the song "The Way We Were". I felt a kinship with the description of his own subliminal imagery by Faw (2009). I see what is around me, unless my eyes are closed when all is always black. I hear, taste, smell and so forth, but I don't have the experience people describe of 
hearing a tune or a voice in their heads. Curiously, I do frequently have a tune going around in my head, all I am lacking is the direct experience of "hearing" it. I think the likely effect of aphantasia on me is to increase my reliance on the verbal over the visual, and to enhance my interest in the abstract rather than the concrete. I have an ability to jump between concepts very easily, but people have commented that I often forget to explain how these apparently frictionless leaps happened. I think it may have contributed to making me more interested in questions than answers, and problems rather than solutions, because I am always aware of the caveats surrounding an idea, and the different possibilities that could be adopted, and am not focused on a visual model of what to do. It does also have some prosaic consequences like making it harder to orient myself in open country (whereas a town, rich in shop names, street signs and so on is relatively easy).

SDAM, meanwhile, is manifest in the way I experience the past and future. When I think about past events in my life I am aware that I was there, and frequently aware of details that are personal, and not told to me by others. I may also be aware of where people were sitting relative to me, and what colour their clothes were. I saw the film Vertigo a few days ago, and still have a sense of the rich redness of the restaurant from the scene where James Stewart first sees Kim Novak. I have a feeling that that I can form and store some sort of unseen quasi-spatial memories. What I don't have is the experience that people describe of feeling that they are back in another time and re-living it. This doesn't mean that I am untroubled by the past or future, quite the opposite, it just means that the past really is "another country" to which I have no passport. Like A E Housman I can feel nostalgia for "the land of lost content ... the happy highways where I went, and cannot come again", but unlike him I don't "see [the land] shining plain". It is much harder for me to assess the difference SDAM has made to me compared to aphantasia. My guess is that its most important effects have been to do with forward planning, which uses the prospective memory. This is certainly the potentially affected area that I feel the greatest actual need to improve. The philosopher Galen Strawson (Strawson,2004) has made the interesting suggestion that some (perhaps most?) people have a strong sense of themselves as having a continuous "story-arc", and has labelled them as "Diachronic", in contrast with his own "Episodic" outlook, where "the way I am now is profoundly shaped by my past, but it is only the present shaping consequences of the past that matter, not the past as such", very reminiscent of the Markovian concept in mathematics, where the next state of a system is only determined by its present one. Importantly, he notes that this is not identical with what he calls the Narrative or non-Narrative experience of life, and isn't straightforwardly coupled to whether one has episodic memories or not (as apparently he does).

I was already 35, and working as a physicist in Cambridge, when a half-page newspaper column (Bywater, 1997) first tipped me off about the real meaning of phrases like "the mind's eye" and "bringing back memories", which up until then I can only assume I took to be figures of speech. The author, Michael Bywater, immediately grabbed my attention by asserting that time "is an illusion but you can never tell what's going to do the trick. You don't believe me? Ask any theoretical physicist or better still, an actual physicist if you can find one ... but he won't tell you what the trick is because he doesn't know ... If he did [...] he'd open a business: time rolled back while you wait". He went on, brilliantly and concisely, to describe the "state of mind where the past is not just a collection of memories but a sanctuary, and you strive to get back there and you can't", and talk about "the process of Rolling Time Back. You choose a memory, focus on it, let the rest of the mind go blank, and wait". I suddenly realized that not only did I not "see" pictures in my mind, but that I also had no "Proustian" recall of the type he described: whether pictures, sound, or any other sensory memory. He captured the quality of episodic memory that William James referred to: "Memory requires more 
than mere dating of a fact in the past. It must be dated in my past" (Greenberg and Knowlton, 2014). When coupled with projection into one's own future this is the ability that Tulving was one of the first to call "mental time travel", seeing it as a quintessentially human ability (Falk, 2008).

What intrigues me most about his piece in retrospect is that there was nothing exclusively visual about his description, it is as much aural, sensual and textural, as for example his recall of "the special weight of girls in autumn ... when they lean against you as you walk along". Nonetheless I was made aware simultaneously of my total absence of waking visual imagery, and of the kind of memory that much later I was to learn is called "episodic", in a context that immediately linked these two deficits.

Both for my own personal peace of mind, and because I am a scientist, I was very curious about these deficits, but for the next ten years or so much of what I had to go on was the testimony of my friends, family and colleagues. I fortunately felt able to talk quite freely to them, but none were aphantasic, and all reported that they possessed episodic memory. These sources were supplemented with what I could glean from the web and occasional glimmers of insight from excellent but still somewhat tangential books like (Kosslyn,1994) and (Schacter, 1996). Because of this scarcity of information, coming upon Galton (1880) and James (1890) within a year or two was the key next step for me, and as a physicist I was naturally intrigued by Galton's conclusion that "scientific men as a class have feeble powers of visual representation", although I was finding even from my own first enquiries that this was not the case among the present-day scientists I spoke to, and a careful re-analysis of his own data does not really substantiate his view (Brewer and Schommer-Aikins, 2006). Importantly, Galton's work explicitly linked imagery and memory, and was thus of relevance to both my deficits, though I tended not to distinguish them initially and simply thought of them as a missing "visual memory". Unfortunately I didn't start keeping a diary, but I think my overwhelming reaction was to wonder why I had never encountered this aspect of his work, especially because as a physicist I was aware of many of his pioneering contributions to statistics, although I understood that his role as a founder of eugenics has made him an unavoidably problematic figure.

I could have stopped my enquiry right there in the late $19^{\text {th }}$ century, but the natural immediate question was what had happened to this field of research since then, and whether a fuller scientific explanation of my situation now existed. I soon encountered the account by Thomas (1997) of the "iconophobia" of J B Watson and Knight-Dunlap, and reports of how, after early progress like the Columbia University PhD thesis by Betts (1909), the scientific study of mental imagery had experienced a very long eclipse in the first half of the $20^{\text {th }}$ century before the renaissance later confirmed to me by other sources such as Mancosu et al (2005), MacKisack et al (2016) and Keogh and Pearson (2017). I was intrigued by the suggestion that Watson may have been aphantasic (Faw, 2009) though this is clearly a contested point (Thomas, 1997). I was struck, however, by the relative sparseness of available information, and sympathized with the view of Thomas (2014) in a post originally written for the Psyche-D forum in 2001: "so far as I have been able to discover (and I have looked, and have asked those who might be expected to know), although the existence of people who deny having visual imagery has been known to science for well over 100 years (Galton, 1880, 1883), no systematic research whatsoever has been done on the phenomenon."

Over the next 10 years or so my incessant web searches and the growing volume of online archived papers in neurology, philosophy, and other relevant disciplines led me to more clues, though I found much more related to imagery than to memory. The appearance of online discussions containing 
non-imagers' own testimony was undoubtedly important to me, particularly one at the Psyche-D forum (later digested at web pages maintained by Nigel Thomas (Thomas, 2014)); one moderated by philosopher Tony Birch (Birch, 2003); and a third responding to a blog post by Dan Schmidt (Schmidt, 2010), not least because they were the first reassurances I received that my experience was probably relatively common. An example is the account of Jim Jablonski, one of the earliest posters to (Birch, 2003): "My consciously projected images seem to wash out in the glare of my conscious mind ... I am not looking to be cured. I find it hard to believe that no one has studied this image problem and hasn't given it a nice Greek name".

However, for various reasons I "lurked" rather than taking part in forums, not least of which was a concern about how I might be seen professionally in my own field of physics, having already been rather more open on the subject with colleagues than was perhaps entirely prudent. I was also concerned about the ethics of leading other people to realise they have a possibly unchangeable memory deficit (as opposed to an imaging one). Even now I am still not sure how useful this selfknowledge is, but the widespread public discussion of SDAM and Aphantasia has made the point rather moot.

In the absence of any obvious interest from modern science, and because of the intrinsically crossdisciplinary nature of the topic, I was very eclectic in my reading. One intriguing pointer was to a self-taught inventor from the counterculture, Wally Minto, who was already, in the 1970s, very aware of different visual and non-visual modalities of thought, and tailoring his "alpha awareness" training to them (Mangum,2001). Instances in art included a song, "No mind's eye" (Mecca Normal, 2002), by a Canadian art rock band in which songwriter Jean Smith talks about her father's professed aphantasia, again linking it to memory: "look down at your hands, can you see them when you were small, picking raspberries". She also recently wrote a novel (Smith, 2014) in which a painter, Gordon, "does pink and orange abstracts that he allows his son Frank to name. The paintings don't have a basis in reality until young Frank decides what they depict. This is unnerving to Gordon who claims not to have a mind's eye". Another aphantasic character in fiction is the male protagonist of the novel "Lying in bed" (Landis, 1995).

Eventually, though, I did start to come across relevant modern scientific work, in part because I was starting to find the right keywords. An important example was the "visual memory deficit amnesia" of Rubin and Greenberg (1998). Despite the intriguing title, the patients described in this paper were not like me but instead had developed amnesia due to a brain injury. However it did offer me significant evidence for a link between image and memory, because of their finding that the loss of imagery appeared to have such a powerful effect on the ability to re-experience episodes. It also gave me an interesting example of a recent scientific paper quoting Galton (1880) as evidence for its assertion that: "many individuals with no known neurological damage report that they do not experience visual images while awake". Over time I encountered various other relevant imaging studies such as that of Cui et al (2007), in which fMRI was used in concert with Marks' Vividness of Visual Imagery (VVI) score, and in which individual differences in vividness were quantifiable. Another interesting example is Logie et al (2010) whose work was informed by the Zeman et al (2010) study of Patient MX, who had lost the subjective experience of imagery after an operation, but who retained the ability to perform many of the tasks that he would have previously used it for.

With hindsight the public discourse was in a strangely divided state, as realised at the time by Brewer and Schommer-Aikins (2006) who noted that there was a substantial continuing literature that accepted, and even amplified, Galton's claims both generally and as they applied to scientists 
(including James (1890), Paivio (1971) and Kosslyn (1980), even as another literature (e.g. Ferguson, 1977) dwelt, as I have done in the previous section, on self-reports of how "imagery has played an important role in the thinking of many great scientists". They did, however note that Galton's questionnaire did not distinguish clearly between imagination and memory.

After about 7 years I began email approaches beyond my immediate circle, which at first either drew no reply, or professions of scepticism. While not unkind, they were not very encouraging either, so the next real breakthrough for me came in 2009 when I found the work of Bill Faw, the first aphantasic person I communicated with, who had just published an excellent review (Faw, 2009) from a standpoint somewhere between the philosophical and neurological that was informed very much by his own experience. His surveys of a total of 2500 people are the source for his widely quoted (e.g. Zeman et al, 2015) but provisional estimate that as many as $2 \%$ of the population may be aphantasic, a finding similar to that of Betts (1909). His situation was ostensibly exactly like mine in that he had no visual imagery, willed or otherwise, as he recounted well in the review: "I close my eyes, I see nothing. I silently think, silently read, with no voice. I'm haunted by silent tunes. When asleep I have frequent vivid and occasionally lucid dreams in all sensory modalities."

The next key step was finding Oliver Sacks' account (Sacks, 2007) of how taking amphetamines in the 1960 s had temporarily changed the nature and extent of his own very weak voluntary imaging abilities. "I ... could hold very accurate and stable visual images in my mind and trace them on paper, as with a camera lucida. ... My enjoyment of these newfound powers ... was mitigated, however, by finding that my abstract thinking was extremely compromised. When, decades later, I read of Bruce Miller's patients and of Allan Snyder's experiments, I wondered whether the amphetamines might have caused a transient temporal lobe disinhibition". It raised the intriguing possibility that I might indeed be able to "switch on" the imagery by some means-though not amphetamines !-with the obvious corollary of wondering whether this would give me a capacity to experience episodic memory, but damage my ability to think abstractly which is rather essential for my work in theoretical physics. I wondered if a form of temporal lobe inhibition might be a physiological or psychological explanation for my own experience, and, if so, what could have given rise to this.

More immediately, Sacks' writing on his experience spurred me to email him in 2010. Receiving a handwritten reply from him that included his New Yorker article "The Mind's Eye" (Sacks, 2003), which by then he was expanding into the last chapter of a book (Sacks, 2010), was deeply inspiring and touching and played a major part in motivating me to stay on the trail. He told me that "I'm very much a non-imager and I suppose a verbalizer myself. I would score zero with every item in Galton's questionnaire, but-somehow-I seem well able to describe events, even enabling others to picture them vividly. I still have a fairly strong episodic memory-I do not know how to account for these apparent contradictions." I was however very puzzled by the paradox that he highlighted, of his being aphantasic in the strict (i.e. voluntary) definition of Zeman et al (2015) and yet possessing an episodic memory, as I was already quite sure I completely lacked one.

Sacks' reference to episodic memory seems to have prompted me to distinguish more clearly between imagination and memory. Prompted in part by this, the final "Eureka" moment for me was when I came across Endel Tulving's seminal work on the distinction between episodic and semantic memory, and the stories of amnesic patients Henry Molaison (HM) and Kent Cochrane (KC), both now deceased, in late 2010, thirteen years after reading Bywater. This time I didn't fail to see the importance of episodic memory, and my web searches about Tulving quickly revealed that he had already predicted in an interview on the Science.ca website (later published in (Shell, 2006)) that 
otherwise healthy people without episodic memory should exist: "animals like his cat have no episodic memory. ... and he believes that some perfectly intelligent and healthy people also lack the ability to remember personal experiences. These people have no episodic memory. They know, but do not remember. Such people have not yet been identified but Tulving believes, they soon will be". This distinction between re-experiencing the past and just "knowing the facts" was amusingly emphasised on the website by a cartoon (Figure 1) where Tulving is interrogating a cat. 


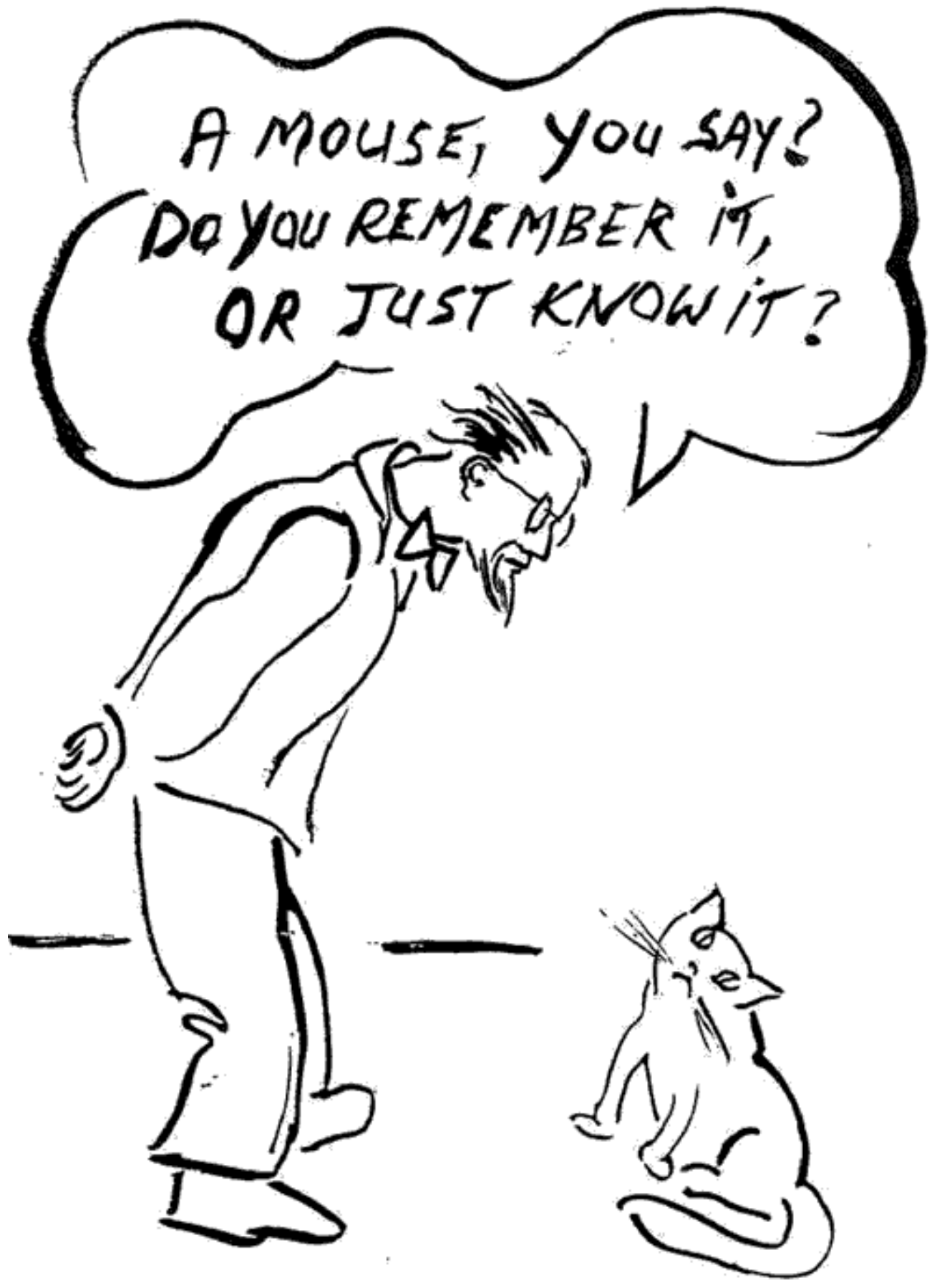

Figure 1: Endel Tulving and the cat (drawing by the late Ruth Tulving).

I wrote to him in January 2011, and although he was essentially retired from research, he directed me to his colleague Brian Levine, and Brian's then PhD student Daniela Palombo, at the Rotman Research Institute in Toronto. I went to Toronto for a week in the summer of 2011 for the tests reported in their paper on 3 individuals with SDAM, including me (Palombo et al, 2015).

When it appeared Palombo et al (2015) had several pieces of evidence about what is happening in my brain, and those of the other two people they tested, when we remember -or more correctly, 
what is not happening in my brain when we don't remember-the neurological "dogs that didn't bark". The most striking evidence is from EEG: the absence of an evoked response potential at 500 ms during successful recognitions that is present in control subjects and associated with reexperiencing. Our recognition is intact, but is thought to be achieved by non-episodic processes.

Additional evidence included the clear visual memory deficit seen on one specific neuropsychological and experimental task, which was, however, the only obvious area of impairment in terms of behavioural assessment. The test was the Rey complex figure test related to sketching a complicated line drawing from memory (Rey, 1941). All of us had a reduction of about $10 \%$ in the right hand hippocampal volume, though this was small compared to developmental amnesics who normally show bilateral reductions of order 30 to $50 \%$ (Varga-Khadem et al, 1997). The investigators' questionnaire showed the demonstrable relative sparseness of our recollected autobiographical detail especially for decades-old memories. Finally, fMRI data showed that some regions known to be associated with autobiographical memory were less activated, including the medial portion of the prefrontal cortex and within the temporal lobes. The reduced activity in the precuneus is notable (Daniela Palombo, personal communication), because this area may be relevant to the mental imagery component (Cavanna and Trimble, 2006; Fletcher, 1995. As well as the three SDAM cases they studied, Palombo et al (2015) referred to two previous cases with a similar profile discussed by (Greenberg \& Knowlton, 2014). In addition, although interpreted within the lesion literature, the patient reported in (Botez, 1985) seems to have many of the attributes of aphantasia and SDAM.

I was initially surprised that one other of the three SDAM cases, Susie McKinnon, in her various interviews concurrent with the publication of the paper (e.g. Branswell, 2015) described an even starker personal experience of episodic memory absence than I do. On reflection, however, I can only assume that, as one would expect, SDAM has degrees of "severity". The division between semantic and episodic memory has recently been supplemented by the intermediate idea of "personal semantics" (Renoult et al, 2012), which perhaps I am using more than she does. I do certainly feel I often have something in memory that is at the same time stronger and more personal than a semantic fact and weaker than the full-blown episodic recall experience. I certainly don't feel that I am "living life in the third person" (Baycrest, 2015), or "stuck in time", and would concur with the view of Craver et al (2014) that more needs to be done to tease out exactly which aspects of temporal consciousness are affected by episodic deficits. It may be that part of the resolution of this puzzle lies in other models such as Paivio's DCT, and that my own consciousness is simply more verbal than visual. It certainly feels this way. However, words, smells, or even music clearly don't trigger the kind of episodic recall in me that so many people describe, even though they can certainly generate a kind of wistful nostalgia.

The publication in early 2015 of the Rotman study was a personal milestone for me, but only a few months later it was followed by a complete surprise-the Zeman et al (2015) paper on Aphantasia in this journal (although I had seen their Zeman et al (2010) study I had never got in contact). One immediate result has been a great increase in the amount of personal testimony on the web about lifetime imagery deficits, from people who recognise aspects of their own experience. I cannot do justice to this explosion here, and the reader is encouraged to explore for themselves in the many new forums, web pages, videos etc already devoted to aphantasia (and SDAM). One thing that has become clear from (Zeman et al, 2015) and the more than 10000 responses the Exeter team have now received is that some but not all aphantasic people have memory deficits (Zeman, 2016). This 
implies that Aphantasia and SDAM are not exactly the same, but poses a question: Is SDAM a subset of "voluntary" or "total" aphantasia, i.e. is the absence of voluntary (or both voluntary and involuntary) imaging a necessary, but not sufficient, condition for SDAM ? At least in principle one could have intact imagery but be deficient in episodic memory (Adam Zeman, personal communication), and indeed there have certainly been cases where people lost episodic memory as a result of injury, having previously had it, and yet reportedly kept their mental imagery. One such example is patient KC whose "ability to visually imagine things ...[was] intact" after the motorcycle accident that severely damaged his episodic memory (Tulving, 2002). But SDAM, like aphantasia, is more narrowly defined, as a lifelong deficit in otherwise healthy people, and I haven't yet seen published reports of people who have that kind of memory deficit innately without also having a deficit in imagery, although I have seen (and mislaid) a self-report in a Tweet by one such individual. It is important to stress here, though, that I am not personally aware of to what extent the key tests of autobiographical memory in aphantasia, and visual imagery in SDAM, have yet been done. 


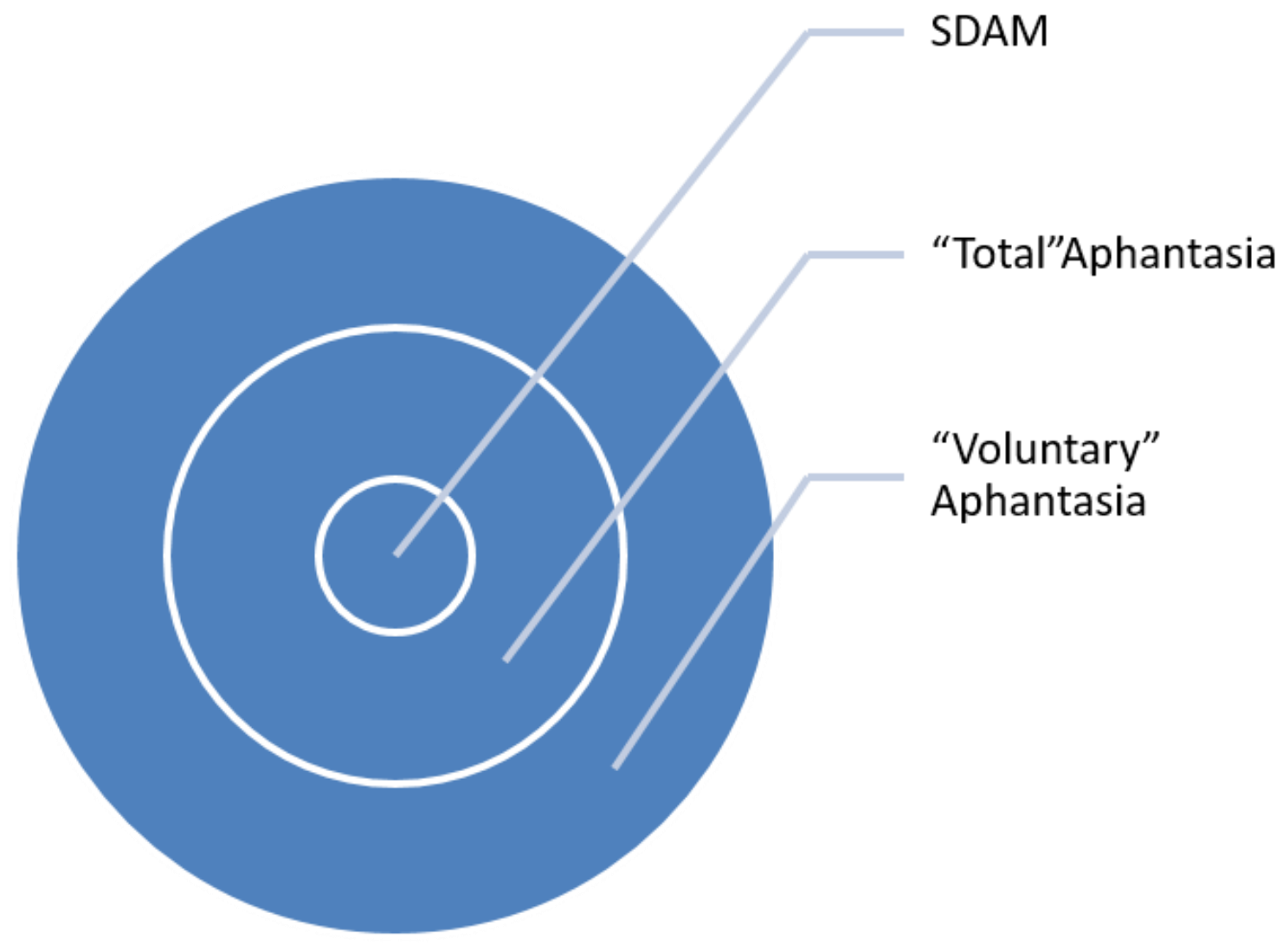

Figure 2: A tentative heuristic diagram illustrating one of several possible ways in which aphantasia and SDAM might be related. It distinguishes between voluntary aphantasia, defined as a lack of voluntary imagery as was originally done in Zeman et al (2015); and complete aphantasia when both voluntary and involuntary imagery are absent. I have placed SDAM, defined purely in terms of episodic memory, in the centre, which corresponds to the possibility that complete aphantasia might be necessary for SDAM. If, for example, there prove to be people who have SDAM but don't lack voluntary imagery, this diagram will need to be modified.

A schematic (Figure 2) illustrates one possible way in which aphantasia and SDAM could differ. As early as 1909 Betts was stressing that "voluntary imagery ... the ability to call up certain specified 
images at will", the focus of much of Galton's interest, was distinct from "spontaneous imagery ... the normal functioning of imagery in the mental process", and noting that a failure to distinguish them had introduced "a certain haziness". As originally coined by Zeman et al (2015), the term Aphantasia only denoted the absence of voluntary images (the outermost ring of Figure 2). This definition would seem to apply to Oliver Sacks. As well as his inability to visualize voluntarily, of which he became aware aged 14 when talking to his mother, a surgeon and strong visualizer (Sacks, 2003;2010), he seems, however, to have been aware of a sparseness in, and possible unreliability of, his memories by his late teens, saying (Sacks, 2001) that the "memory hole" in Orwell's 1984 resonated with his own doubts about his memory and "led to an increase in [his] own journal keeping, and photographing, and an increased need to look at testimonies of the past". It seems clear that this very active personal episodic compensation contributed to the millions of words of personal journal that are mentioned in (Sacks, 2015). However, he seems to have been no stranger to involuntary images, describing them in association both with his own memory of, and his brother's account of, two wartime bombs both in an interview (Silberman, 2002), and in the New York Review of Books (Sacks, 2013): "I can see the bomb in my mind's eye now, Pa with his pump, and Marcus and David with their buckets of water. How could I see it so clearly if I wasn't there?". Indeed, he described the "resonant clonk" of a piece of Tungsten sent by the chemist Roald Hoffmann as serving "as a sort of Proustian mnemonic, [that] instantly brought Uncle Tungsten to mind ... Other pictures rose immediately in my mind ... the memories, now started, continued to emerge, ... many forgotten for fifty years or more."

The kind of complete Aphantasia that has evidently resonated with many peoples' experience, including mine, corresponds to the absence of both voluntary and involuntary imagery, the next ring in the diagram. I think it would be useful to more routinely distinguish between these two definitions as I have done on the schematic, as there have been assertions that such a total absence of imagery may preclude episodic memory altogether. For example, when Greenberg and Knowlton (2014) studied "two people who had no visual imagery [they] found [them to] not only [have] a deficit of visual imagery [but also] an auditory-imagery deficit and a near-complete inability to relive their memories". I have retained SDAM as a third category, but I am thus unclear as to how strong the distinction between it and complete aphantasia is. One key, testable, question here is whether aphantasics who report episodic memories always have them accompanied by images, or whether there is some other nonvisual way of accessing such memories.

After the insights from the combined findings of Palombo et al (2015) and Zeman et al (2015) and the surge of personal testimony that has resulted, one remaining question that I would like to clarify is that of dreams. I am almost certain that I have images in dreams, although my inability to recall them because of the absence of waking imagery makes it impossible to be sure. Clearly some others with aphantasia do so as well, from their accounts. The lingering possibility of a psychological origin for some cases of aphantasia (de Vito et al, 2016; Zeman et al, 2016) means that I would like to be sure that my conscious imagery is not being repressed, although the SDAM paper stated that "there is no evidence to support a neurological or psychiatric explanation" for their findings. Dreaming and voluntary imagery are likely to involve very different circuits (with some overlap) - dream imagery is generated "from below", by activity in the brain stem (e.g. Leu-Semenescu et al, 2013), whereas voluntary imagery is likely to depend on the fronto-parietal cortical executive system (e.g. Zeman et al, 2015;Bartolomeo,2008), so the dissociation isn't greatly surprising (Adam Zeman, personal communication). But it is still unclear to me how a dream can have access to images of people that I know, but can't visualise while awake, something that I am almost sure has happened to me. On the face of it the dream is either accessing otherwise unavailable visual memories, or is randomly 
generating faces that I am "recognising", or believing (in the dream) that I recognise. I am not sure how one could test between recall in a dream and "mere" recognition, and would urge that consideration be given to this.

1.4 Conclusions: I have briefly reviewed some of the literature that exists on mental imagery in science, and noted that the faculty has always been both widely used and treated with caution. However, Galton's finding that some scientists had extremely limited or zero imagery raises questions about the influence this other pole has had on the evolution of science and mathematics which I think should be revisited in the light of the new evidence from Zeman et al (2015) about aphantasia. I have recounted my own experience of becoming aware of my aphantasia and a concomitant memory issue, SDAM, and the work of Palombo et al (2015) in providing objective evidence of the latter. My participation as a research subject for their paper provided me with gratifying empirical evidence that what I thought was happening was indeed real, but, equally, confirmed that it is limited in its scope, and hasn't stopped me living an essentially normal life. It was also satisfying to have made some contribution to science beyond my own enjoyable but limited achievements in physics. I would like to conclude by considering two final points. One is the question of how aphantasia has affected my own science, and the other is how after all this, do I feel about aphantasia and SDAM, what insights have I gained that help me and might help others, and is there anything more I can do ?

My scientific career started with a degree and then PhD in theoretical physics. I thus need to be able to reason abstractly, and to communicate with other scientists, but evidently don't need to be able to picture things. I think with hindsight the influence of aphantasia can be seen in the courses which I preferred. I found quantum mechanics and statistical mechanics to be much more congenial than for example electromagnetic theory, and as a graduate student I particularly enjoyed the third volume of Feynman's lectures in which he developed quantum mechanics almost entirely from considering an abstract spin. Transitioning into space science as a postdoc, and working in the environmental sciences, presented some challenges, particularly in dealing with the widespread use of two-dimensional colour plots, which speakers frequently want their audience to compare with previously shown ones which I now assume they expect people to recall. A growing understanding of my thinking style has since helped me to work with colleagues, especially Sandra Chapman who is a strong visualiser and enjoys precisely those spatial, 3-dimensional areas of physics that didn't appeal to me. My collaboration with her began when she saw a computer screen displaying a simulated trajectory from a quantum mechanical problem I had studied in my PhD, that had the same form as problems in electromagnetic theory that she was interested in. The equations came only later. I also wonder if the fact I lost interest in chemistry at school about the same time as we started doing organic chemistry may have had some connection to my inability to visualise complex molecules. Oliver Sacks' deep love of chemistry (c.f. Sacks, 2001) might seem to caution against such an interpretation, but apparently he was much more interested in inorganic chemistry than organic (Kate Edgar, personal communication).

Even 20 years on, I am still ambivalent about my awareness of aphantasia and SDAM. For a long time I felt that I would have been happy to leave the apple on the tree of knowledge, as it were, and go on as blithely unaware of these issues as I had been for most of my life. The most touching expression of the frustration I sometimes feel from this loss of innocence came from Mcalpine (2016): "So ... if I had a neurotypical mind's eye, I could do this too? I would be able to see pictures of my [family and] ... friends, like a slideshow or even a movie? ... How healing that would be if I were sick, or when I become old in body and afraid. I allowed myself to weep at this terrible loss of 
something that (as far as I know) I have never had. I let rip with delicious self-pity for two minutes. That's more than enough". I can only aspire to her self-discipline, or the sense of wonder at his own aphantasia shown by Blake Ross, a founder of Firefox (and screenwriter): "I think what makes us human is that we know we're the galactic punchline but we can still laugh at the set up. The cosmos got me good on this one. How beautiful, though, that such electrical epiphany is not just the province of the child." (Ross, 2016)

After many years seeking clues in relative isolation, my contacts with Sacks and Faw, and then being a research subject in a careful and thorough scientific study on a small sample, the dizzying explosion of new knowledge and testimony resulting from the widespread publicity about aphantasia left me reeling for a while, feeling rather like one of the starship travellers in a favourite science fiction novel from my childhood (Heinlein, 1963). After years of dangerous voyaging between a handful of stars in the (relatively) near neighbourhood of the sun, the greatly depleted crew is picked up by people who have now found out how to travel faster than light and can return them to earth in an afternoon! But I eventually came to realise that if I had to become aware of it at all I am glad I pursued the subject myself, and that I didn't become aware of it only just recently from the attention surrounding the SDAM and aphantasia papers. I think this is because although I do indeed feel SDAM as a deficit, and a difference, I am ambivalent about the presumption some people have leapt to that both it and aphantasia must automatically be disabling. In particular even my own career suggests that it isn't true that aphantasic children must be at an educational disadvantage (Costandi, 2016). I rather think that the way I have had to compensate for aphantasia and SDAM has been at the root of many of my talents as well as my limitations, and indeed my semantic memory has been something I have been able to rely on for most of my life.

I am though still left with one of the questions that originally motivated me, what else, if anything, can I do to compensate for my deficits? In my case the answers are different for SDAM and aphantasia. Visualisation is something that I don't really experience as an absence, it is rather something I am simply curious about, much as one might wonder what it might be like to be of a different gender, or live in a different era. I am intrigued by anecdotal reports of people increasing their imaging ability, including for example some postings to (Birch, 2003), and I know that some aphantasics that I and others have spoken to are keen to do this. As far as I know, though, the conclusions of Rademaker and Pearson (2012) typify a current academic consensus that voluntary or involuntary imagery probably cannot be increased from its total absence, as opposed to being increased when already present. I share the ambivalence expressed by Grinnell (2016) about having such a faculty returned to me after its absence for so long, and would want to be able to "switch it off" if I didn't like having it. Whether this consensus changes, or new technological prosthetic aids rather like those of the Black Mirror episode "The Entire History of You" (Brooker, 2011) appear in my lifetime, will be one of the developments I am most curious to see.

SDAM, however, remains rather different, and my memory deficit really does sometimes feel like an absence or loss. I understand the surprise that many people clearly feel when told that it apparently isn't necessary to have the experience of first person, visual, emotional "mental time travel" into one's own past and future in order to be human. SDAM really doesn't seem to disconnect me from my past and future as much as one might expect, however, consistent with the arguments of Craver et al (2014). Palombo et al (2015) put it well when they said people with SDAM "experience the past in the absence of recollection". I am still very much a product of my own past, it's just that I can't subjectively go back there. A good example of what I do have is my experience of seeing Holst's St Paul's suite performed in London on a (Puffin Club) school outing in the early 1970s. I have no 
emotion-laden episodic memory of being there, but nonetheless somehow know that I found it joyous, and feel that it helped me towards a lifelong love of classical music. As far as I understand the meaning of Renoult et al's "personal semantics" this memory is of that type, in that the event was personal rather than shared with other family members.

An awareness of SDAM has made some things I already had more precious to me. Family photograph albums, or my own sketches in the scrapbooks I compiled as a spaceflight-obsessed teenager, have come to replace an episodic memory by in some sense becoming the memories. I have also been fortunate to live at a time where both a personal and a global episodic memory have become available artificially from technologies like smartphone cameras and YouTube. I have for example searched for a remembered fragment of a lyric in order to find a TV show credit sequence last seen when I was a child. The web has also been a great boon in its ability to find evidence that something did indeed happen as I think I remembered it, for example live recordings from concerts I went to decades ago.

I have now started to be more proactive in working around my memory deficit, by using a tool that Oliver Sacks recounted to us when Sandra Chapman and I finally met him in New York in 2014. He was at that time working on the last volume of his memoirs (Sacks, 2015) and told us how he had found that dictating them during a long car journey around North America had helped him to recall episodes. Using sound recordings of my talks and interviews (and their transcriptions) has been useful, not only by prompting recall of forgotten details but to try and relive the associated enthusiasm and energy.

I was also intrigued by the technology of video lifelogging by wearable cameras. The pioneering Sensecam from Microsoft Research which was used in trials by amnesia researchers (Laurson, 2009) was followed by commercial offerings such the currently unavailable Autographer and Narrative Clip. I was tempted, but the latter's dependence on cloud storage, and possible antipathy from the public due to lack of familiarity with such devices, were two factors that have stopped me so far, though I hope the technology will return in some form. Something like the combination of the Narrative Clip with Google Glass that was investigated by NYU Stern school (Mishkin, 2015) could be a remarkably appealing asset. Perhaps one day prosthetics like this will seem no more remarkable than the spectacles that I have worn since about the age of 6 .

In the end, though, all of us try to transcend whatever fate has placed in our way, and I am aware of what a fortunate life I have in fact had. I would thus like to end with some words that have inspired me. On aphantasia, I feel that the beautiful summing up from Sacks (2003) conveys how there is much more to imagination than mental imagery: "Such powers may be invaluable, but [they are ] ... utterly different from the higher and more personal powers of the imagination, where there is a continual struggle for concepts and form and meaning, a calling upon all the powers of the self. Imagination dissolves and transforms, unifies and creates, while drawing upon the "lower" powers of memory and association. It is by such imagination, such "vision," that we create or construct our individual worlds. At this level, one can no longer say of one's mental landscapes what is visual, what is auditory, what is image, what is language, what is intellectual, what is emotional-they are all fused together and imbued with our own individual perspectives and values." This resonates strongly with the perspective of many of the artists who responded to Susan Aldworth on the subject of aphantasia (Aldworth, 2016).

Strawson (2004), meanwhile, quotes the $3^{\text {rd }}$ Earl of Shaftesbury [1671-1713] to remind us that we 
are not just our memories (square brackets indicate his interpretations): "The metaphysicians... affirm that if memory be taken away, the self is lost. [But] what matter for memory? What have I to do with that part? If, whilst I am, I am as I should be, what do I care more? And thus let me lose self every hour, and be twenty successive selfs, or new selfs, 'tis all one to me: so [long as] I lose not my opinion [i.e. my overall outlook, my character, my moral identity]. If I carry that with me 'tis I; all is well. ... - The now; the now. Mind this: in this is all."

And the last word is from Sandra Chapman, written while she was contemplating the sea at St Ives, Cornwall, and thinking about the many and diverse ways we can aggregate our past and present experiences to make the selves we carry forward into the future:

All of the oceans I have seen

are in this ocean, in between

each wave, each sigh, a thousand lands

a thousand dreams and miracles

Acknowledgements: I am grateful to my partner Sandra Chapman, my parents, brother and sister and many other people for their help and encouragement during my investigations, in particular Andy Bereza, Ed Bullmore, Michael Bywater, Matt Coles, Ed Collier, Colleen Cotter, Daniel Crow, Sarah Delfont, Kate Edgar, Bill Faw, Sarah Jane Hall, Henrik Jensen, Caroline Lambard, Brian Levine, Nick Moloney, Bill Nuttall, Charles Ogilvie, Daniela Palombo, Mike Pinnock, the late Oliver Sacks, Endel Tulving, Paul Warwick, Adam Zeman, and all the participants who made the 2016 Eye's Mind meeting such a rich and valuable experience.

\section{References:}

Aldworth, S. (2016), The Art of Imagination, talk slides from presentation at "The Eye's Mind", http://medicine.exeter.ac.uk/media/universityofexeter/medicalschool/research/neuroscience/docs/ theeyesmind/The Art of Imagination Susan Aldworth.pdf

Bain, A. (1880), Mr Galton's Statistics of Mental Imagery, Mind, 19, 564-573.

Bartolomeo, P. (2008). The neural correlates of visual mental imagery: an ongoing debate. Cortex, 44, 107-108.

Baycrest (2015) Press Release, April 20 ${ }^{\text {th }}$ http://www.baycrest.org/news/living-life-in-the-thirdperson-cognitive-scientists-discover-clues-in-the-brain-to-an-extraordinary-memory-glitch-inhealthy-high-functioning-people/

Benfy, O. T. (1958). August Kekule and the birth of the structural theory of organic chemistry in 1858. Journal of Chemical Education, 35(1), 21-23.

Betts, G. H. (1909) The distribution and functions of mental imagery. New York: Teachers' College, Columbia University.

Birch, A. (moderator), Quicktopic discussion thread from 2003 onwards http://www.quicktopic.com/20/H/Z85yvCpH8FP 
Botez, M. I.; Olivier, M.; Vezina, J.-L.; Botez, T.; Kaufman, B. (1985) Defective revisualization, dissociation between cognitive and imagistic thought. Case report and short review of the literature. Cortex, 21, 375-389.

Branswell, 2016, Toronto Star, https://www.thestar.com/life/2015/04/28/susie-mckinnon-cantremember-events-in-her-life-just-facts.html

Brewer, W. F. and Schommer-Aikins, M. (2006). Scientists Are Not Deficient in Mental Imagery: Galton Revised. Review of General Psychology, 10(2), 130-146.

Brooker, C. (2011). Black Mirror series 1 episode 3, "The entire history of you" https://en.wikipedia.org/wiki/The Entire History of You

Burbridge, D. (1994) Galton's 100: an exploration of Francis Galton's imagery studies. British Journal for the History of Science, 27, 443-63.

Bywater, M. (1997) How to have fun without taking your clothes off. Independent on Sunday. $7^{\text {th }}$ December.

Cavanna, A. E.; Trimble, M. R. (2006) The precuneus: a review of its functional anatomy and behavioural correlates. Brain, 129(3), 564-83.

Costandi, M. (2016). If you can't imagine things, how can you learn ? The Guardian, Saturday $4^{\text {th }}$ June. https://www.theguardian.com/education/2016/jun/04/aphantasia-no-visual-imaginationimpact-learning

Craver, C. F., Kwan, D., Steindam, C., Rosenbaum, R. S. (2014) Individuals with episodic amnesia are not stuck in time. Neuropsychologia. 57, 191-195.

de Vito, S., Bartolomeo, P., (2015), Refusing to imagine? On the possibility of psychogenic aphantasia. A commentary on Zeman et al. (2015), Cortex, doi: 10.1016/j.cortex.2015.06.013.

Dirac, P. A. M. (1930) The Principles of Quantum Mechanics. Oxford: Oxford University Press.

Dungey, J. (1986) Jim Dungey in conversation with David Stern, EOS, 67(51), December $23^{\text {rd }}$.

Falk, D. (2008). In Search of Time. New York: Thomas Dunne Books.

Farmelo, G. (2009) The Strangest Man: The Hidden Life of Paul Dirac, Quantum Genius.

Faw, W. (2009) Journal of Consciousness Studies,16(4), 45-68

Ferguson, E. S. (1977) The Mind's Eye: Noverbal Thought in Technology. Science, 197, 827-836.

Fletcher, P.C., Frith, C.D., Baker, S.C., Shallice, T., Frackowiak, R.S., Dolan, R.J. (1995) The mind's eye-precuneus activation in memory-related imagery. Neuroimage. 2(3), 195-200. 
Galton, F. (1880) Statistics of Mental Imagery, Mind, 19, 301-318.

Galton, F. (1883) Inquiries into Human Faculty and Its Development, http://www.gutenberg.org/files/11562/11562-h/11562-h.htm

Greenberg, D. L. and Knowlton, B (2014) The role of visual imagery in autobiographical memory, Mem. Cogn., DOI 10.3758/s13421-014-0402-5

Grinnell, D. (2016). Blind In The Mind. New Scientist, $20^{\text {th }}$ April. https://www.newscientist.com/article/2083706-my-minds-eye-is-blind-so-whats-going-on-in-mybrain/

Hadamard, J. (1945) The psychology of invention in the mathematical field, Princeton, N. J.: Princeton University Press.

Heinlein, R. A. (1963) Time for the Stars, London: Victor Gollancz.

Isaacson, W. (2015) The Light-beam rider, New York Times, 30 ${ }^{\text {th }}$ October 2015.

https://www.nytimes.com/2015/11/01/opinion/sunday/the-light-beam-rider.html? $r=0$

James, W. (1890) The Principles of psychology, Volume 2.

https://archive.org/details/principlesofpsyc02jameuoft

Landis, J. D. (1995) Lying In Bed. Algonquin Books.

Laurson, L. (2009). A Memorable Device. Science. 323, 1422-1423. $13^{\text {th }}$ March.

Leu-Semenescu, S., Ugoccioni, G., Golmard, G.-L., et al (2013) Can we still dream when the mind is blank ? Sleep and dream mentations in auto-activation deficit. Brain, 136, 3076-3084.

James, W. (1890). The principles of psychology, Volume 2 http://psychclassics.yorku.ca/James/Principles/

Keogh, R., and Pearson, J. (2017) The blind mind: no sensory imagery in aphantasia, PsyArXiv osf.io/preprints/psyarxiv/pdjb9

Kosslyn, S. (1980) Image and Mind. Harvard University Press.

Kosslyn, S. M. (1994). Image and brain: The resolution of the imagery debate Cambridge, Mass.: MIT Press.

Lawrence, W. (2002) The World of Blind Mathematicians, Notices of the AMS, 49(10), 1246-1251.

Logie, R. H., Pernet, C. R., Buonocore, A., Della Sala, S. (2011). Low and high imagers activate networks differentially in mental rotation, Neuropsychologia, 49, 3071- 3077

Longair, M. (2003) Theoretical Concepts in Physics: An Alternative View of Theoretical Reasoning in 
Physics. (Second edition). Cambridge, UK: Cambridge University Press.

MacKisack, M., Aldworth, S., Macpherson, F., Onians, J., Winlove, C., \& Zeman, A. (2016) On Picturing a Candle: The Prehistory of Imagery Science. Front. Psychol., 7, 515. doi:

10.3389/fpsyg.2016.00515

Mancosu, P., Joergensen, K. F. \& Pedersen, S. A. (2005). Visualisation, Explanation and Reasoning Styles in Mathematics. Synthese Library, Volume 327. Dordrecht: Springer.

B. B. Mandelbrot (1995) interview at Web of Stories, http://www.webofstories.com/play/benoit.mandelbrot/6

B. B. Mandelbrot (2012), The Fractalist: Memoir of a Scientific Maverick. Pantheon Books.

Mangum, C. (2001) series of postings to the EMCOMM list: EMC278 - So What ? It Affects Me (Release 02/26/01); EMC279 - Images, Part 1 (Release 03/05/01); EMC280 - Images Part 2 (Release 03/12/01); EMC281 - Images Part 3 (Release 03/19/01); EMC282 - Images Part 4 (Release 03/26/01) Archived at www.qsl.net/n7fan/emcomm/2001

Mecca Normal, 2002. Song "No Mind's Eye", on LP "The Family Swan". https://www.youtube.com/watch?v=qkW-h1QYPn0

Mcalpine, R. (2016) https://writeintolife.com/2016/05/26/a-writer-with-aphantasia-weird-or-what

Miller, A. I. (1986) Imagery in Scientific Thought: Creating 20 ${ }^{\text {th }}$ Century Physics, Cambridge, Mass.: MIT Press.

Mishkin (2015) Mishkin, S., Wearable technology finds its place on campus, Financial Times, May 10th https://www.ft.com/content/6043098e-f340-11e4-a979-00144feab7de

Paivio, Allan. 1971. Imagery and verbal processes: Holt, Rinehart and Winston.

Paivio, Allan. 1990. Mental representations: A dual coding approach: Oxford University Press.

Paivio, Allan. 2007. Mind and Its Evolution: A Dual Coding Theory Approach. Mahwah, NJ: Lawrence Erlabaum Associates, Inc.

Palombo, D. J., Alain, C., Soderlund, H., Khuu, W., \& Levine, B. (2015) Severely deficient autobiographical memory (SDAM) in healthy adults: A new mnemonic syndrome, Neuropsychologia, 72, 105-118.

Pearson, D. G., C. Deeprose, S. M. Wallace-Hadrill, S. Burnett Heyes, and E. A. Holmes (2013) Assessing mental imagery in clinical psychology: a review of imagery measures and a guiding framework. Clin. Psychol. Rev. 33 (1), 1-23. doi: 10.1016/j.cpr.2012.09.001

Rademaker, R. L., and Pearson, J. (2012) Training visual imagery: improvements of metacognition, but not imagery strength. Front. Psychology, 3, 224. doi: 10.3389/fpsyg.2012.00224 
Renoult, L., Davidson, P. S. R., Palombo, D. J., Moscovitch, M., and Levine, B. (2012) Personal semantics: At the crossroads of semantic and episodic memory. Trends Cogn. Sci., 16(11), 550-558.

Rey, A. (1941) L'examen psychologique dans les cas d'encephalopathie traumatique. (Les problems.) Archives de Psychologie. 28, 215-285.

Rocke, A. (2010) Image and Reality: Kekule, Kopp and the Scientific Imagination. Chicago, III.: University of Chicago.

Ross, B. (2016). Aphantasia: How it feels to be blind in your mind. https://www.facebook.com/notes/blake-ross/aphantasia-how-it-feels-to-be-blind-in-your$\underline{\operatorname{mind} / 10156834777480504}$

Rubin, D. C. and Greenberg, D. L. (1998) Visual memory-deficit amnesia: A distinct amnesic presentation and etiology. Proceedings of the National Academy of Science, 95, 5413-5416

Sacks, O. (2001) Uncle Tungsten. New York: Alfred. A. Knopf

Sacks, O. (2003) The Mind's Eye: What the Blind See, A Neurologist's Notebook, The New Yorker, July 28th, 48-59.

Sacks, O. (2007). Musicophilia. New York: Alfred. A. Knopf.

Sacks, O. (2010) The Mind's Eye. New York: Alfred. A. Knopf.

Sacks, O. (2013) Speak, Memory. New York Review of Books, February 21st.

Sacks, O. (2015) On the Move: Picador

Schacter, D. (1996) Searching for Memory: The Brain the mind and the past. New York: Basic Books

Senechal, M. (1998) The Continuing Silence of Bourbaki-An Interview with Pierre Cartier [Bourbaki 1955-83], June 18, 1997. The Mathematical Intelligencer, 1, 22-28. http://ega-

math.narod.ru/Bbaki/Cartier.htm

Schmidt, D. (2010) http://dfan.org/blog/2010/01/23/i-still-dont-see-anything-when-i-close-my-eyes/

Shell, B. (2006) Sensational Scientists: The Journeys and Discoveries of 24 Men and Women of Science, $2^{\text {nd }}$ Edition. Raincoast books.

Silberman, S. (2002) The Fully Immersive Mind of Oliver Sacks. Wired.

https://www.wired.com/2002/04/sacks-2/

Smith, J. (2014) https://jeansmithwriter.wordpress.com/magnet/

Strawson, G (2004) Against Narrativity. Ratio (New Series). XVII, 0034-0006, 4 December.

Thomas, N. (1997) Mental Imagery. Stanford Encylopaedia of Philosophy.

http://plato.stanford.edu/entries/mental-imagery/ 
Thomas, N. (2014) Are There People Who Do Not Experience Imagery ? (And why does it matter ?) Blog post 2001-2013 archived at https://webbeta.archive.org/web/20141015073105/http://www.imagery-imagination.com:80/non-im.htm Tulving, E. (2002). Episodic memory: from mind to brain. Annu. Rev. Psychol. 53, 1-25.

Watkins (2016). Mandelbrot's 1/f fractional renewal models of 1963-67: The non-ergodic missing link between change points and long range dependence. Preprint arXiv:1603.00738v1[stat.OT]

Wuetrich, A. (2010) The Genesis of Feynman Diagrams. Archimedes, Volume 26. Dordrecht: Springer. Zabusky, N. J. (1984) Computational Synergetics. Phys. Today. 37(7), 36-46. doi: 10.1063/1.2916319 Zeman, A., Della Sala, S., Torrens, L., Gountouna, E., McGonigle, D., \& Logie, R. H. (2010). Loss of imagery phenomenology with intact visual imagery performance. Neuropsychologia, 48, 145-155.

Zeman, A., Dewar, M., \& Della Sala, S. (2015). Lives without imagery - Congenital aphantasia. Cortex, 73, 378-380 http://dx.doi.org/10.1016/j.cortex.2015.05.019

Zeman, A. (2016). 10000 People Make Contact Over Visual Imagery. The Exeter Blog, http://blogs.exeter.ac.uk/exeterblog/blog/2016/11/08/aphantasia-10000-people-make-contactover-visual-imagery/

Zeman, A., Dewar, M., \& Della Sala, S. (2016). Reflections on aphantasia. Cortex, 74, 336-337. DOI:10.1016/j.cortex.2015.08.015 